Int. J. Electrochem. Sci., 14 (2019) 9098 - 9111

\title{
Electrochemical Sensor Platform for 8-Hydroxy-2'- Deoxyguanosine Detection Based on Carboxyl-Functionalized Carbon-Allotropic Nanomaterials Wrapped Gold Nanoparticles Modified Electrode
}

\author{
Zhengjun Yi, Jinjuan Qiao, Ying Wang, Kunshan Gao, Ronglan Zhao* and Xiangying Meng* \\ Department of Laboratory Medicine, Weifang Medical University, Weifang, Shandong 261053, PR \\ China \\ *E-mail: mengxiangying85730@126.com, ronglanzhao@wfmc.edu.cn
}

doi: $10.20964 / 2019.09 .77$

Received: 12 May 2019 / Accepted: 14 July 2019 / Published: 5 August 2019

\begin{abstract}
As a typical biomarker of oxidative DNA damage, 8-hydroxy-2'-deoxyguanine (8-OHdG) has received considerable attention in recent years, because elevated levels of urinary 8-OHdG are typically associated with various diseases related to oxidative stress. However, the accurate identification and quantification of $8-\mathrm{OHdG}$ in human urine is generally confounded by its trace content and complex matrices. In this work, a facile and effective electrochemical sensor for urinary 8-OHdG detection was constructed based on carboxyl-functionalized carbon-allotropic nanomaterials (GO-COOH/MWCNTs$\mathrm{COOH}$ ) wrapped gold nanoparticles ( $\mathrm{Au} \mathrm{NPs}$ ), which resulted in modified electrode. The sensing material consisting of GO-COOH, MWCNTs-COOH, polyethyleneimine (PEI), and Au NPs was fabricated by self-assembly of negatively charged Au NPs onto positively charged PEI-wrapped GO$\mathrm{COOH}$ and MWCNTs-COOH through electrostatic interactions. The electrochemical experiments demonstrated that the biosensor showed high electrochemical performance on the oxidation of 8OHdG and efficiently alleviated the interferences from uric acid (UA) with the help of uricase. According to differential pulse voltammetry (DPV) results, the oxidation peak currents correlated linearly with the concentration of $8-\mathrm{OHdG}$ in the ranges of $0.014-0.14 \mu \mathrm{M}\left(\mathrm{R}^{2}=0.9916\right), 0.14-1.41$ $\mu \mathrm{M}\left(\mathrm{R}^{2}=0.9954\right)$, and $1.41-14.12 \mu \mathrm{M}\left(\mathrm{R}^{2}=0.9915\right)$ with a detection limit $(\mathrm{S} / \mathrm{N}=3)$ of $7.06 \mathrm{nM}$. In addition, the results of analytical detection of 8-OHdG in human urine samples were satisfactory with a very high recovery percentage. Therefore, it is believed that the proposed sensor is a promising candidate for risk assessment of various diseases related to oxidative stress.
\end{abstract}

Keywords: 8-Hydroxy-2'-deoxyguanine; Electrochemical biosensor; Gold nanoparticles; Carboxylfunctionalized graphene oxide; Carboxyl-functionalized multi-walled carbon nanotubes 


\section{$\underline{\text { FULL TEXT }}$}

(C) 2019 The Authors. Published by ESG (www.electrochemsci.org). This article is an open access article distributed under the terms and conditions of the Creative Commons Attribution license (http://creativecommons.org/licenses/by/4.0/). 